\title{
Dispersion Characteristics of the Dominant Mode on a Completely Shielded Conductor-Backed Slotline
}

\author{
Jan Zehentner, Jan Machac, Jan Mrkvica \\ Czech Technical University in Prague, Technicka 2, 16627 Prague 6, Czech Republic
}

\begin{abstract}
This paper presents an analysis of a completely shielded conductor-backed slotline using the spectral domain technique. Attention is paid to dominant and higher order modes with even symmetry of the transversal electric field component in the slot parallel to the dielectric interface. The dependence of the phase constant and the characteristic impedance of the line on cross-sectional size, permittivities and frequency are given. It has turned out that the line is suitable for circuit design when the dominant requirement is for low characteristic impedance. Numerical examples highlight particular aspects of the mode propagation over the line. The consequence of setting $\varepsilon_{0}$ in the whole cross-section of the line is a waveguide containing a partition in the $H$ plane with a longitudinal slot. An analysis of this guide by the spectral domain method is presented and typical frequency dependent phase constant and characteristic impedance patterns are shown.
\end{abstract}

Index Terms - Dominant mode, planar transmission line, shielded conductor-backed slotline, waveguide slotted partition.

\section{INTRODUCTION}

Recently we have investigated the dispersion characteristics of the conductor-backed slotline, Fig.1a $\left(\varepsilon_{1}>\varepsilon_{2}=\varepsilon_{3}=\varepsilon_{0}\right)$, and the modified inverted conductorbacked slotline, Fig. 1a $\left(\varepsilon_{1}<\varepsilon_{2}>\varepsilon_{3}=\varepsilon_{0}\right)$, [1,2]. The line was assumed to be lossless and unbounded in the longitudinal and transversal directions. We have investigated the modes leaking power in the substrate and also in space. However, it turned out that for circuit application the line has to be shielded from the sides and the top, Fig. 1b. This line exhibits interesting behaviour depending on the crosssectional size and the permittivities in the upper and lower portion.

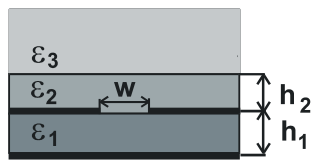

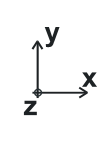

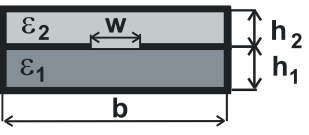

b
Fig. 1. (a) Cross-section of the conductor-backed slotline when $\varepsilon_{1}>\varepsilon_{2}=\varepsilon_{3}=\varepsilon_{0}$ and the modified inverted conductor-backed slotline when $\varepsilon_{1}<\varepsilon_{2}>\varepsilon_{3}=\varepsilon_{0}$, (b) Cross-section of the shielded conductor-backed slotline, $\varepsilon_{2}<\varepsilon_{1}$.
Many planar slotted transmission lines with different cross-sections have been analyzed by the integral equation method in the space domain [3]. In this paper we present an analysis of the completely shielded lossless conductorbacked slotline (SCBSL) by the method of moments in the spectral domain. The dispersion characteristics of the dominant mode are studied and shown in dependence on the line parameters viewed from the practical point of view. The conclusions may assist in the design of this line, meeting specific requirements originating from the circuit function and set, e. g., on the operation frequency band and characteristic impedance.

\section{ANALYSIS OF THE LINE}

In accordance with the spectral domain technique [4], we applied the Fourier transform of the $\mathrm{z}$ component of the electric and magnetic Hertz potential in the $\mathrm{x}$ direction on the finite interval $b$

$$
\widetilde{\Phi}\left(\xi_{\mathrm{n}}, \mathrm{y}\right)=\frac{2}{\mathrm{~b}} \int_{-\mathrm{b} / 2}^{\mathrm{b} / 2} \Phi(\mathrm{x}, \mathrm{y}) \mathrm{e}^{-\mathrm{j} \xi_{\mathrm{n}} \mathrm{x}} \mathrm{dx}
$$

where $\xi_{n}=2 n \pi / b$ and $n=0, \pm 1, \pm 2, \ldots \infty$. The solutions of their wave equations in the y direction, in the two regions of the cross-section, are known. Consequently, the field components are available in the spectral domain. Imposing the boundary conditions at the plane $\mathrm{y}=\mathrm{h}_{1}$, transformed also in the spectral domain, we get algebraic equations relating the unknown transversal and longitudinal components of the current densities with the unknown transversal and longitudinal electric field components by the dyadic Green's functions in the Fourier transformed domain. Now we expand the electric field components within the slot in terms of known basis functions. Because the electric fields and currents are nonzero in complementary regions at the interface $\mathrm{y}=\mathrm{h}_{1}$, the current densities can be eliminated using Galerkin's method and Parseval's theorem. Finally we get a set of linear homogeneous algebraic equations for unknown amplitudes of the basis functions. Their nontrivial solution is obtained by setting the determinant of the equations equal to zero. The record of this condition is the well 
known dispersion equation. It is fulfilled for the desired propagation constant of the dominant and higher order modes.

Another important quantity, essential for the design of circuits, is the characteristic impedance of the dominant mode. Because it is a hybrid mode, the definition of the characteristic impedance is not unique. We shall use hereafter the power-voltage definition

$$
\mathrm{Z}=\frac{\mathrm{V}^{2}}{2 \mathrm{P}}
$$

where $\mathrm{V}$ is the voltage across the slot

$$
V=\int_{-w / 2}^{w / 2} E_{x}(x) d x
$$

$\mathrm{V}$ can be evaluated, since integrand $\mathrm{E}_{\mathrm{x}}(\mathrm{x})$ is defined by the field series expansion within the slot and by the known amplitudes of the basis functions computed in the propagation constant search. $\mathrm{P}$ is the time-averaged power flow

$$
P=\frac{1}{2} \operatorname{Re} \int_{-b / 2}^{b / 2} \int_{0}^{h_{1}+h_{2}}\left(E_{x} H_{y}^{*}-E_{y} H_{x}^{*}\right) d y d x .
$$

By applying Parseval's theorem in (4) we get

$$
\begin{aligned}
\mathrm{P}= & \frac{\mathrm{b}}{4} \operatorname{Re} \sum_{\mathrm{n}=-\infty}^{\infty} \int_{0}^{\mathrm{h}_{1}+\mathrm{h}_{2}}\left[\widetilde{\mathrm{E}}_{\mathrm{x}}\left(\xi_{\mathrm{n}}, \mathrm{y}\right) \widetilde{\mathrm{H}}_{\mathrm{y}}^{*}\left(\xi_{\mathrm{n}}, \mathrm{y}\right)\right. \\
& \left.-\widetilde{\mathrm{E}}_{\mathrm{y}}\left(\xi_{\mathrm{n}}, \mathrm{y}\right) \widetilde{\mathrm{H}}_{\mathrm{x}}^{*}\left(\xi_{\mathrm{n}}, \mathrm{y}\right)\right] \mathrm{dy}
\end{aligned}
$$

and P can now be computed in the spectral domain.

\section{DISPERSION CHARACTERISTICS AND CHARACTERISTIC IMPEDANCE}

The $E_{x}(x)$ component in the slot can have even or odd symmetry with respect to the line axis. The electric field $E_{x}(x)$ with even symmetry is technically easily excitable. Therefore, for the purposes of experimental verification of the theoretical findings, we inquired, first of all, into the even dominant mode and also into the characteristics of the even higher order modes. We checked the correctness of our code by computing the dominant mode phase constant on the SCBSL, a special case of the fin line given in [5]. Published data agreed well with ours. However, it should be noted that the dominant mode of the SCBSL with the lowest cut-off has odd symmetry of the $\mathrm{E}_{\mathrm{x}}(\mathrm{x})$. This mode and the odd higher order modes are beyond the scope of this paper. Consequently, we discuss hereafter only even modes on the SCBSL.

The transversal component of the electric field $\mathrm{E}_{\mathrm{T}}(\mathrm{x}, \mathrm{y})$ of the even dominant mode and the first higher order mode are shown in Fig. 2. The field $\mathrm{E}_{\mathrm{y}}(\mathrm{x}, \mathrm{z})$ seen from the top in the upper and lower dielectric is shown in Fig. 3.
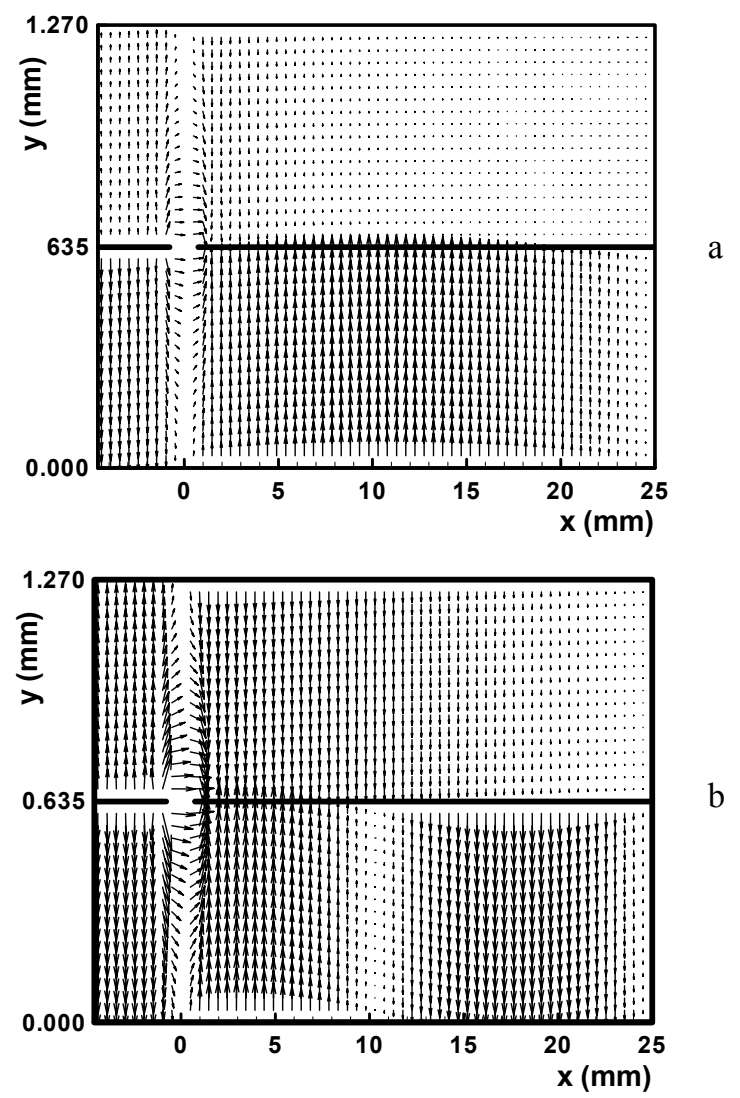

Fig. $2 \mathrm{E}_{\mathrm{T}}(\mathrm{x}, \mathrm{y})$ of the dominant mode (a) and the first higher order mode (b), when $\mathrm{h}_{1}=\mathrm{h}_{2}=0.635 \mathrm{~mm}, \mathrm{w}=1.5 \mathrm{~mm}, \mathrm{~b}=50 \mathrm{~mm}$, $\varepsilon_{\mathrm{r} 1}=10, \varepsilon_{\mathrm{r} 2}=1, \mathrm{f}=3.5 \mathrm{GHz}$.

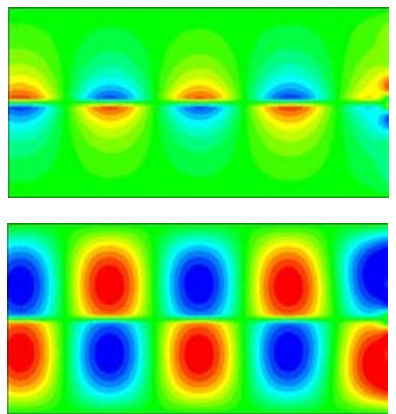

a
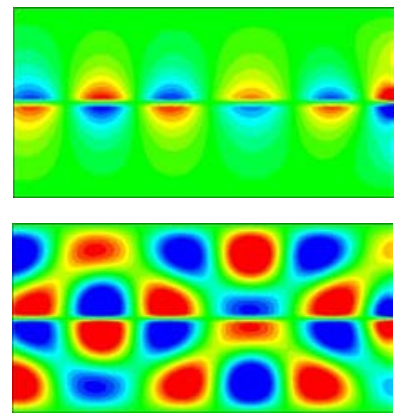

b
Fig. $3 \mathrm{E}_{\mathrm{y}}(\mathrm{x}, \mathrm{z})$ of the dominant mode at $\mathrm{f}=2.5 \mathrm{GHz}$ (a) and the first higher order mode at $\mathrm{f}=4 \mathrm{GHz}(\mathrm{b})$ when $\mathrm{h}_{1}=\mathrm{h}_{2}=0.635 \mathrm{~mm}$, $\mathrm{w}=1.5 \mathrm{~mm}, \mathrm{~b}=50 \mathrm{~mm}, \varepsilon_{\mathrm{r} 1}=10, \varepsilon_{\mathrm{r} 2}=1$.

Obviously the concept of transversal resonance can be applied for calculating the cut-off frequencies $f_{c}$ of the modes. Let the slotwidth $\mathrm{w}$ be less than $\lambda_{\varepsilon} / 2$ in the higher 
permittivity dielectric. Then the upper parallel plate guide with the propagation constant $\mathrm{k}_{2}=\mathrm{k}_{0} / \sqrt{\varepsilon_{\mathrm{r} 2}}$ and characteristic impedance $Z_{2}=Z_{0} / \sqrt{ } \varepsilon_{\mathrm{r} 2}$ in the $\mathrm{x}$ direction, short circuited at the $\mathrm{x}=\mathrm{w} / 2$, is connected in parallel to the lower short circuited parallel plate guide with $\mathrm{k}_{1}=\mathrm{k}_{0} / \sqrt{ }_{\varepsilon_{\mathrm{r} 1}}$ and $\mathrm{Z}_{1}=\mathrm{Z}_{0} / \sqrt{ } \varepsilon_{\mathrm{r} 1}$. Their common port placed at $\mathrm{x}=\mathrm{w} / 2$ is terminated by the capacity $\mathrm{C}=\left[\cot \left(\mathrm{k}_{2} \mathrm{l}\right) / \mathrm{Z}_{2}+\cot \left(\mathrm{k}_{1} \mathrm{l}\right) / \mathrm{Z}_{1}\right] / \omega_{\mathrm{c}}$, where $\mathrm{l}=(\mathrm{b}-\mathrm{w}) / 2, \omega_{\mathrm{c}}=2 \pi \mathrm{f}_{\mathrm{c}}$. Since the right hand side of this formula, including $\mathrm{f}_{\mathrm{c}}$, is known from our computation, $\mathrm{C}$ can be determined. Conversely, we can calculate $\mathrm{f}_{\mathrm{c}}$ from the same transcendent formula setting known $\mathrm{C}$. For example when $\mathrm{h}_{1}=\mathrm{h}_{2}=2 \mathrm{~mm}, \mathrm{w}=1 \mathrm{~mm}, \mathrm{~b}=50 \mathrm{~mm}$, $\varepsilon_{\mathrm{r} 1}=10, \varepsilon_{\mathrm{r} 2}=1$, then $\mathrm{C}=0.17 \mathrm{pF}$ and, conversely $\mathrm{f}_{\mathrm{c}}$ of the first four modes 1.161, 2.747, 4.404, $5.831 \mathrm{GHz}$ are calculated with error less than $1.5 \%$.

The dispersion characteristics of the SCBSL are shown in Fig. 4. They change very slightly with the slot-width. The permittivity growth pulls the characteristics to lower frequencies, as shown in Fig. 5, while the width of the frequency band of pure dominant mode propagation remains essentially the same. An increase in permittivity of the lower dielectric results in substantial growth of the phase constant. The cut-off of the dominant mode falls with line width $b$. For example, $\mathrm{f}_{\mathrm{c}}=8.72$ and $0.88 \mathrm{GHz}$ for $\mathrm{b}=5$ and $50 \mathrm{~mm}$, respectively, when $\mathrm{w}=0.5 \mathrm{~mm}, \mathrm{~h}_{1}=5 \mathrm{~mm}$, $\mathrm{h}_{2}=0.3 \mathrm{~mm}, \varepsilon_{\mathrm{r} 1}=20, \varepsilon_{\mathrm{r} 2}=2.6$. The smaller the value of $\mathrm{b}$, the greater is the change of the cut-off when the slot-width $\mathrm{w}$ changes. Practically, if $b=5 \mathrm{~mm}, \mathrm{w}=0.5$ and $1.5 \mathrm{~mm}$, then $\mathrm{f}_{\mathrm{c}}=8.72$ and $10.22 \mathrm{GHz}$, respectively, while for $\mathrm{b}=50 \mathrm{~mm}$ and the same change in the slot-width, $\mathrm{f}_{\mathrm{c}}=0.88$ and 0.89 $\mathrm{GHz}$, respectively. A high value of $\mathrm{b}$ enables excitation of higher order modes.

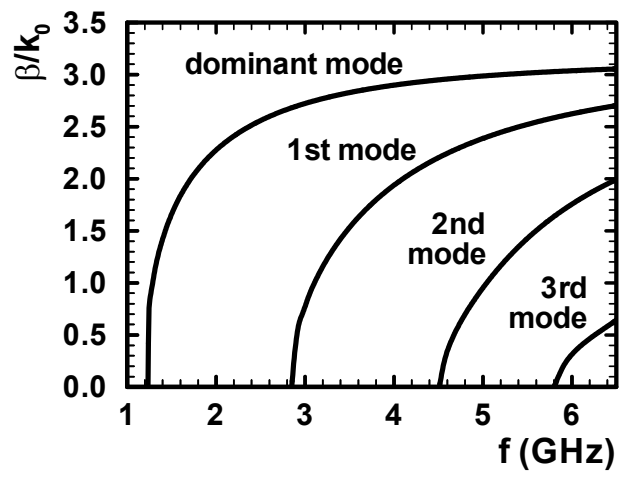

Fig. 4 Normalized phase constant of the even dominant and three higher order modes on the SCBSL when $\mathrm{h}_{1}=\mathrm{h}_{2}=0.635 \mathrm{~mm}$, $\mathrm{w}=0.5 \mathrm{~mm}, \mathrm{~b}=50 \mathrm{~mm}, \varepsilon_{\mathrm{r} 1}=10, \varepsilon_{\mathrm{r} 2}=1$.

Fig. 6 shows the measured phase constant of the even dominant mode tracing the calculated characteristic well. The standing wave on the SBCSL was detected by a movable probe over the longitudinal slot in the shielding placed where the longitudinal component of the magnetic field $\mathrm{H}_{\mathrm{z}}(\mathrm{x})$ was zero.

The characteristic impedance of the SCBSL is very low, as shown in Fig. 7, and depends strongly on the line width b. $\mathrm{Z}$ is actually constant over $85 \%$ of the frequency band of pure dominant mode propagation.

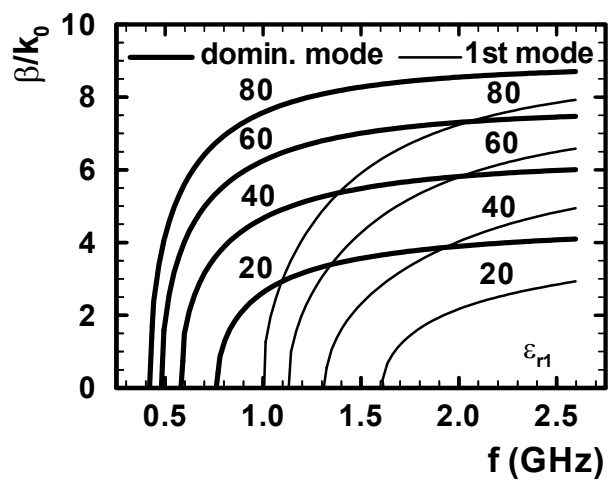

Fig. 5 Normalized phase constant of the even dominant and the first higher order mode on the SCBSL, when $\mathrm{h}_{1}=\mathrm{h}_{2}=0.635$ $\mathrm{mm}, \mathrm{w}=0.5 \mathrm{~mm}, \mathrm{~b}=50 \mathrm{~mm}, \varepsilon_{\mathrm{r} 1}=20,40,60,80, \varepsilon_{\mathrm{r} 2}=10$.

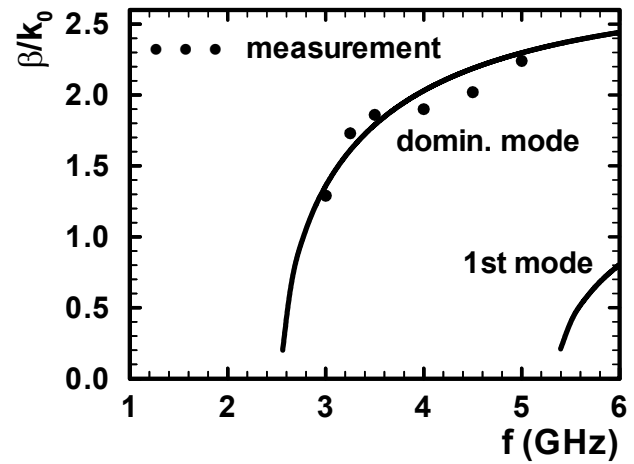

Fig. 6 Calculated and measured phase constant of the even dominant mode on the SCBSL with $\mathrm{h}_{1}=\mathrm{h}_{2}=0.635 \mathrm{~mm}, \mathrm{w}=1.5$ $\mathrm{mm}, \mathrm{b}=50 \mathrm{~mm}, \varepsilon_{\mathrm{r} 1}=10, \varepsilon_{\mathrm{r} 2}=1, \mathrm{f}=3.5 \mathrm{GHz}$

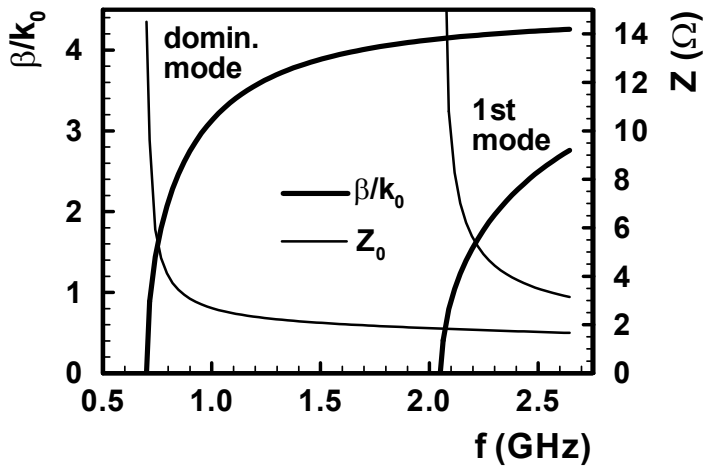

Fig. 7 Characteristic impedance and normalized phase constant of the SCBSL when $\mathrm{w}=1.5 \mathrm{~mm}, \mathrm{~h}_{1}=5 \mathrm{~mm}, \mathrm{~h}_{2}=0.3 \mathrm{~mm}$, $\mathrm{b}=50 \mathrm{~mm}, \varepsilon_{\mathrm{r} 1}=20, \varepsilon_{\mathrm{r} 2}=2.6$. 


\section{Rectangular WAVEguide PARTITIONED IN THE H PLANE}

The spectral domain method applied in analyzing the SCBSL is also suitable for analysis of a rectangular waveguide containing a conductive partition in the $\mathrm{H}$ plane with the longitudinal slot, $\varepsilon_{1}=\varepsilon_{2}=\varepsilon_{0}$ in Fig. 1b. The frequency dependences of the phase constant and the characteristic impedance now resemble those for the TE modes in the rectangular waveguide, and $\beta / \mathrm{k}_{0}$ is less than 1. The ratio $(w / b)$ substantially influences the cut-off. The higher the value of $w / b$, the higher is $f_{c}$. By analogy, the ratio $\left(h_{2} / h_{1}\right)$ shifts $f_{c}$ considerably. The greater the value of $\mathrm{h}_{2} / \mathrm{h}_{1}$, the greater is $\mathrm{f}_{\mathrm{c}}$, Fig. 8. An increase in $\mathrm{h}_{2} / \mathrm{h}_{1}$ simultaneously lowers the characteristic impedance, as is shown in Fig. 9.

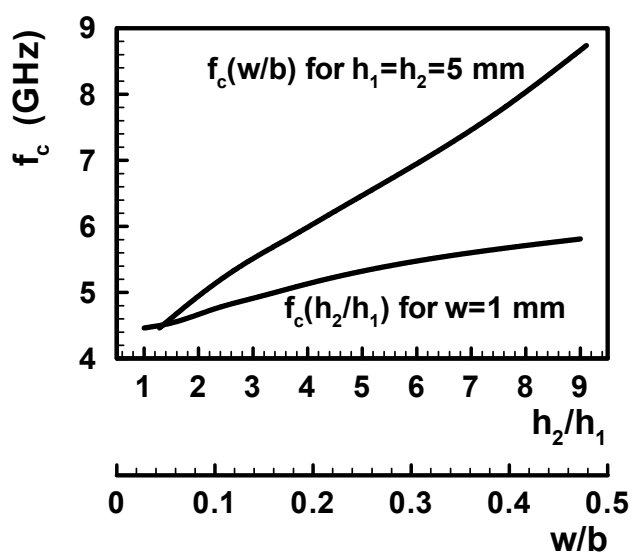

Fig. 8 Dominant mode cut-off in the rectangular waveguide with partition in the $H$ plane when $h_{1}+h_{2}=10 \mathrm{~mm}$ and $b=23 \mathrm{~mm}$.

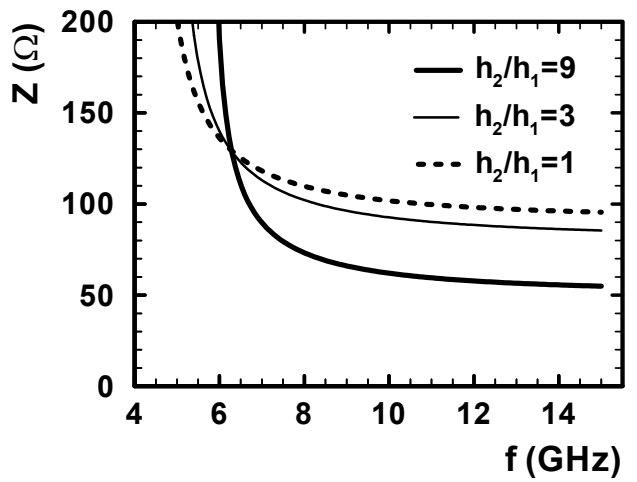

Fig. 9 Characteristic impedance of the rectangular waveguide with partition in the $\mathrm{H}$ plane when $\mathrm{h}_{1}+\mathrm{h}_{2}=10 \mathrm{~mm}, \mathrm{w}=1 \mathrm{~mm}$ and $\mathrm{b}=23 \mathrm{~mm}$.

\section{CONCLUSION}

A hybrid mode with odd symmetry of $E_{x}$ in the slot is the dominant mode of the completely shielded conductorbacked slotline. Modes with even symmetry of $E_{x}$ in the slot have also the dominant mode. Its cut-off is higher than the cut-off of the former, and falls with an increase in the line-width $b$ and with an increase in either permittivity. The slot-width $\mathrm{w}$ does not play an essential role, except for narrow lines with small $b$. Variation of the field distribution with frequency has been shown, and the presence of dominant and higher order modes has been documented. Generally, the characteristic impedance of the SCBSL is low, so the line is suitable for parallel mounting of devices. The frequency band of pure dominant mode propagation is $30-40 \%$ of the mid-band frequency and $\mathrm{f}_{\mathrm{c} 1} / \mathrm{f}_{\mathrm{c}} \approx 2$ for most lines.

The phase constant and the characteristic impedance of the rectangular waveguide with an inserted partition in the $\mathrm{H}$ plane with a longitudinal slot is a by-product of our SCBSL analysis. This results in the possibility to design a waveguide with the propagation constant similar to the constant in the rectangular waveguide, but having essentially lower characteristic impedance. The advantage of low losses, i. e., high $\mathrm{Q}$ factor, of the standard rectangular waveguide is maintained. Parallel mounting of devices across the slot is easy.

\section{ACKNOWLEDGEMENT}

This work has been supported by the Grant Agency of the Czech Republic under project 102/03/0449 "New circuit devices for communication technology".

\section{REFERENCES}

[1] J. Zehentner, J. Machac, J. Mrkvica, C. Tuzi, "Modes on the standard and inverted conductor-backed slotline," 2003 IEEE MTT-S Int. Microwave Symp. Dig., vol. 2, pp. $677-$ 680, June 2003.

[2] J. Zehentner, J. Machac, J. Mrkvica, C. Tuzi, "The inverted conductor-backed slotline - a challenge to antenna and circuit design," Proc the 33rd European Microwave Conference, vol. 2, pp. 73-76, September 2003.

[3] V. A. Neganov, E. I. Nefyodov, G. P. Jarovoy, Elektrodynamicheskye metody proektirovanya ustroystv SVCH $i$ anten, Moskva: Radio i svyaz, 2002.

[4] B. Bhat, S. K. Koul, Analysis, design and applications of fin lines, Norwood: Artech House, 1987.

[5] L.-P. Schmidt, T. Itoh, "Spectral domain analysis of dominant and higher order modes in fin-lines," IEEE Trans. Microwave Theory \& Tech., vol. 28, no. 9, pp. 981-985, September 1980. 